\title{
Research on Wushu Culture of Southwest Pictorial Stone Brick of Han Dynasty
}

\author{
Zexiu $\mathrm{Ai}^{1}$ Zhenhua Guo ${ }^{2}$ \\ 1. Wushu department, Chengdu Sport University \\ Chengdu, China \\ e-mail:316225603@qq.com \\ 2. Sports Scientific College, Jishou University \\ Jishou,China \\ e-mail:jsdxgzh@126.com
}

Keywords : Wushu Culture; Pictorial Stone Brick of Han Dynasty; The Han Dynasty

\begin{abstract}
This paper studies Wushu culture of southwest pictorial stone/brick of han dynasty using the methods of literature material method, field investigation method and related knowledge such as discipline of ethnology, cultural geography, history cultural geography and so on. The study finds that: In Han dynasty, with the augmentation of the exploitation of the unified empire, the martial arts culture of southwest went through the development course of an increasing prosperity, the various aspects such as the generalization, a standard, the diversity of Wushu culture and so on have gained unprecedented development. The regional cultural phenomenon presented that Chinese martial arts culture acted as the main body, martial arts culture of ethnic minorities was complementary. The closure of the geographical environment and the increasing scale of migration, the improve traffic conditions, made southwest Wushu culture have the characteristics of closure and open; The increasing of the military war promoted the development of martial arts; The diversity of ethnic groups promoted the diversity of Wushu culture; Influenced by religious consciousness, Wushu culture appeared rich WuHua and indigenous color. Short weapons were used universally, especially the crossbow developed greatly. The study aims to better research southwest sports culture of Han dynasty, and to provide reference for southwest sports culture construction.

In Southwest China, there are many kinds and forms of pictorial carved stones with wide distribution and mass varieties. They have been found in the east of Sichuan province, city of Chongqing, Yi autonomous prefecture of Liangshan in southwest Sichuan, north of Guizhou province as well as Chaotung of Yunnan province, within which there is a large amount in the middle west of Sichuan Basin, the central area of Bashu area of Han dynasty, and those pictorial stones in the middle and late period of Eastern Han dynasty are the most popular. Usually the contents of carved stones are about field hunting and shooting, music and dance, and animals and beasts and so on, which reflects the colorful and prosperous martial art in Han dynasty.
\end{abstract}

\section{Martial art of Pictorial Carved Stones of Han Dynasty in Southwest China as well as their Forms}

Ontology of Martial Art. In Han dynasty, the Southwest martial arts are of different kinds which are integrated with daily life and wars. Patterns of Southwest stone portraits of Han dynasty include bare-handed fighting, weight lifting, ancient fighting, weapon stabbing, single weapon dance, pair exercise and other martial arts competition. On the copper reserve unit unearthed from Jinning at M1:5, there are eight warriors who are competing martial arts with sword, spear, ax, arch and stick and so on, which reflects Southwestern minorities' history of loving martial arts and practicing martial arts. The stone portrait of boxing unearthed from Yihe of Sichuan Pengzhou shows a scene of pair fighting. The weight lifting is used by army to measure soldiers' strength including lifting gate 
door bolt, tripod and stones. Southwest weight lifting of Han dynasty was spread widely. One of the earliest empirical materials by far in China about weight lifting is the "Portrait of Powerful Man" at the cliff tomb in Santai county, city of Mianyang, Sichuan province.

In Han dynasty, ancient fighting played an important role in social life and production. During Qin-Han times, the ancient fighting was not only popular in the army, but it was also popular among folk people. Stone portrait of "Shuixi-extension of ancient fighting" discovered in county of Pi, Sichuan province contained ancient fighting play, shield dance, ax dance and battle-axe dance.

The amount of arsenal in Southwest areas indicates a deep martial spirit among Southwest minorities of Han dynasty as well as the development history of the weapons and martial arts. The "Weapon Figure" unearthed from the Zeng tomb of Han dynasty in Chengdu displays a life and production picture with weapons life spiked sword, spear, trident fork and halberd and so on.

Fencing was quite popular in Han dynasty. According to the Han system, everyone should be equipped with sword from emperor to officers. There are special teachers for fencing lessons with an initial school of fencing. Fencing performance is very common on Southwestern pictorial carved stones of Han dynasty. Stone portraits of sword dance and jump shot in Mountain Yangzi of Chengdu as well as the picture of "Martial Art Performance" of Eastern Han all express this theme.

\section{Shooting Activity}

\section{1) Archery}

Archery in the Southwest was employed in the war as early as in the Neolithic periods. By Han dynasty, shooting activity had been well developed, involved wars, archery exercise, archery dance, hunting and outdoor activities, during which archery and shooting were very popular. Crossbow is another long-distance weapon with powerful lethality, which had been applied to war during Warring States Periods, and it was further developed in Han dynasty. In Southwest China of Han dynasty, three forms of opening crossbow are advocated, that is, stand opening, seated opening and armed opening. These ways of crossbow archery were well depicted in the stone picture in Neijiang, Leshan and Mianyang in Sichuan province.

2) Horsemanship

The occupation of horse trainer was early appeared in the late Neolithic Periods in Southwest areas and it was very universal in the late Spring and Autumn Periods. Pictures of horse performance also appeared on the wall pictures by Bo people in Southwest areas, in which one Bo stands on a running horse back and performs difficult actions, which displays the brave spirit of Bo people.

\section{3) Riding technique}

In Bashu area, driving technique was very common in stone pictures, indicating a high level. Axe vehicle was the remains of ancient war vehicle. The axe vehicles found on the stone pictures of Han dynasty in Pengzhou and Chengdu were right the ancient war vehicles. Covered wagon was also called horse wagon. On the right side and behind the vehicle, there is one person respectively with a long spear in the left hand and a broadsword in the right hand, protecting the wagon to run safely.

Hunting. In Southwest areas of Han dynasty, farming was coexistent with nomadic people who were good at hunting with super skills because it is both a survival skill and a recreational activity. The forms of hunting can be different such as shoot hunting, rope hunting and circle hunting and so on. Arches and crossbows were used for hunting since marks can be found from the stone pictures about shootings in caves in Guizhou for the bird shooting as well as Sichuan Pengzhou for the Lotuspicking and so on.

Beasts Competition. Beasts' competition was played by brave people which showed their bravery and wisdom, and it could also be used to train fighting skills. At that time of Han dynasty, "play with leopard and perform with brown bear" and "compete with horse and tigers" were adored by Han people. There are many stone pictures about competing with tigers, apes and ox. For example, the "Struggle with Tiger" carved in Ya'an depicted a fight between a warrior and a tiger, during which the warrior was ready to sting the tiger, reflecting the brave spirit of Han people in the Southwest. 
Martial Art Activities in Acrobatics. Acrobatics in Han dynasty was known for its risk and excite. On one hand, it is combined with dance and music; on the other hand, it also integrated with many other activities like ancient fighting, dance, sword flipping, pyramid and handstand and so on, which was called acrobatics uniformly with colorful forms and of certain risk and difficulty. It played an important role in people's social life. Handstand was known as a universal recreational form, including handstand with props, handstand on pyramid as well as handstand on the floor.

Martial Art in Exorcising Dance. The exorcising dance was popular in Southwest areas. The White Tiger and the Elephant Man which are found on the sarcophagus in county of Fushun, the Elephant Man which is found on the cliff tomb stone in Chengdu as well as the Elephant Play which is found in Luzhou and Ya'an all reflected the worship of exorcising dance. By holding sticks and swords during the dance, people hoped to dispel ghost and welcome luck. Such kind of dance is still popular in today's Southwest China.

\section{Analysis on the Causes of Martial art in Southwest Han Dynasty}

The martial art in Southwest areas contains both the basic connotation and general characteristics of Chinese martial culture, but it has some unique features which are different from other areas for its special natural environment, social environment as well as humanistic atmosphere. Affected by its own production way, way of living, way of thinking as well as behavioral ways, and the martial art in this region has formed its own distinctive characteristics.

Natural Environment. Wushu culture, as one kind of cultural behaviors, is deeply affected by the natural environment it lies in. The types of martial activities can be directly decided by the land forms and geography. Southwest areas in Han dynasty had complicated topography and inconvenient transportation for the high mountains and deep valleys as well as crossed waters, which formed a natural barrier for the cultural communication, accumulation and oriented deposit. It seemed that culture there was original without a uniformed civilization. The closer to the martial cultural zone of Han dynasty, the deeper effect it will have; otherwise, it will be less. Meanwhile, Southwest areas have rich forest resources and lots of mountains, which formed unique martial culture for the archery, hunting, and climbing as well as beast competition.

Social Transition. After Han controlled the rule, the emperor established feudal rule from the central government to local governments nationwide, which seriously impacted the politics, culture and economy in Southwest areas unprecedentedly. The original tribes and clan groups in Southwest experienced drastic social transition, making the Wushu culture transform to Han culture. Emperor $\mathrm{Wu}$ of Han advocated the system of prefectures and counties with large scale of exploiting, so the mainstream martial culture in central plains such as archery and driving skills spread to Southwest areas, which strongly impacted the indigenous Wushu culture in Southwest areas especially the cultural center, Sichuan.

Mode of Production. During Qin-Han times, there were many modes of economy and production coexistent in Southwest areas. According to the records in Shi Ji-Records of Southwester Peoples, some peoples in Sichuan and Yunnan areas were living on farmlands, but some were nomadic peoples, which indicated the variety of their ways of living and production. Besides, there were dense forests and broad grassland in Southwest areas, which provided assurance for hunting. The Wushu culture was closely related to the way of production. The tough character as well as superior riding skills and precise archery skills were right cultivated in the long-term process.

Economic Development. The development of social materials and labors is the necessary precondition for the development of martial culture. The Southwest areas made a great progress on agriculture with more varieties and amounts of iron tools, playing an important role nationwide. Most land in Southwest areas was exploited. Therefore, Sima Qian once wrote in the Records of Southwestern Peoples that land was fertile in Sichuan and Yunnan areas as well as surroundings. The abundant products had provided solid material basis for martial activities; besides, during industrial 
and mineral trades, the martial culture had been further developed with more frequent communication, which contributed to a rich and colorful martial culture to meet the people's need for cultural life in Southwest areas.

Military Activities. Peoples in Southwest China were very brave and adored military activities with certain strength of army. In Han dynasty, there were frequent wars in Southwest areas. The situation of army marching to the boundary from the words of attack and army in the historical events can be imagined. After the Southwest was conquered by Emperor Wu of Han, wars occurred within the ruling classes, competing for land and population with sharp conflicts and frequent wars. Both the contents and training means of martial culture were greatly enriched through a series of military activities, which promoted the development of martial culture. The brutal wars required new demands for soldiers' military skills and physical qualities, and thus archery, driving, war wagon competition, running, fighting and flipping were widely carried among folk people, which extremely enriched the contents and means of martial culture.

Trade and Transportation. As early as in ancient times, our forefathers in Southwest areas began to exploit the mountains and open ways by cutting down bamboos and making boats as well as setting up chains in the air. After experiencing lots of risks and dangers, a lot of mountain roads, water ways and bridges were built, creating the brilliant Southwestern transportation culture. The Southwestern Silk Road with a long history right embodied such kind of culture. In the $2^{\text {nd }}$ century $\mathrm{BC}$, Zhang Qian was sent to visit Yue tribe, and on his way he found the devious roads in Sichuan to India, which lasted for thousand miles. Afterward, he went to India through this road for several times, which was called the Southwestern Land Silk Road. Later, this road had been constantly explored which promoted the communication among different peoples and different nations. Meanwhile, it also helped to spread the martial culture in Southwestern areas.

Immigration. As early as in Qin-Han Periods, inland people began to migrate to Southwest. During the War States periods, Zhuang Qiao led army to Yunnan so as to guard the State of Chu, which left deep influence on the military and martial culture there. It can be seen that the marks of military and martial culture from the bronze weapons unearthed from Southwestern areas. During pre-Qin period, the Qiang tribe also migrated to the Southwest from Northwest. During Qin-Han times, the Yue area was seriously impacted for the strict rule and development by central government, leading to large change of population distribution, within which some people migrated to the Southwest China, which helped to enrich the contents of martial art culture and promote the expansion of Wushu culture in space with more frequent communication with other cultures.

Factors of Religion. People in the Southwest had been worshiped witchcraft for a long history. Different kinds of Wushu culture have been inherited by witchcraft. Witchcraft, dance and martial art are similar to each other, which have been combined together for a long time. They were seen as one by aborigines. According to the Explanation of Words and Characters, witchcraft stands for luck. Wizard dance was an important activity. In ancient times, dancers were called witches, and witches were also called dancers. According to survey, there have still been over 20 kinds of wizard dances left in Bai minority, such as Whip dance of conqueror, chain dance and stick dance. Those who worship witchcraft believe that witches have super power to suppress ghost and evils.

\section{Conclusion}

In Han dynasty, as the empire was becoming powerful with deeper exploration, the Southwestern martial art culture experienced a gradual process of prosperity. The Wushu culture achieved unprecedented development to be universal, stereotype and various, presenting a regional cultural phenomenon with Han people as the main part while minorities as the supplement. Affected by Han culture, Wushu culture in Sichuan area was the most developed especially in Chengdu which could be seen as the core of Southwestern Wushu culture together with its surroundings; while Yunnan and Guizhou were relatively backward, so Wushu culture was covered with deep aboriginal features. They 
were fond of short weapons, especially for crossbows and arches. It will be a complicated project to study Southwestern Wushu culture by studying pictorial carved stones of Han dynasty, requiring complete and serious analysis, summary and reflections so that better develop and study the stone martial art culture.

\section{Acknowledgment}

State General Administration of sport open-end funds key research base of national sports topics(14jdzb023).

\section{Reference}

[1] (Tang dynasty) Fang Xuanling. Book of Jin(1) [M]. Beijing: Chinese Book Store, 2000:499.

[2] The Edition Commission for the Complete Works of Chinese Stone Portraits. Sichuan Stone Portraits of Chinese Complete Pictorial Carved Stones.[M] Zhengzhou: Henan Press of Art, 2006:26.

[3] Wenyou. Selections of Sichuan Stone Portraits of Han Dynasty[M]. Public Press, 1955:150.

[4] Gong Tingfang, Gongyu. Works of Stone Portraits of Han Dynasty in Sichuan[M]. Beijing Press of Cultural Relics, 1988:112.

[5][6]Dong Zhian. Collected Works of Han Dynasty. The $18^{\text {th }}$ Volume[M]. Jinan: Press of Shandong University, 2009:10976.

[7][8][9][10][11][12] (Han dynasty) Sima Qian. Illustrations of Historical Records[M]. Nanjing: Phoenix Publishing House, 2012:490.

[13](Tang dynasty) Fanchuo. Collations and Annotations of Southwestern Book[M]. Beijing: Zhonghua Book Company, 1962:31. 